\title{
Dietary fiber intake and reduced risk of ovarian cancer: a meta-analysis
}

\author{
Bowen Zheng ${ }^{1 \dagger}$, Hui Shen ${ }^{2 \dagger}$, Hedong $\mathrm{Han}^{3+}$, Ting $\mathrm{Han}^{2^{*}}$ and Yonghong Qin ${ }^{1^{*}}$ (D)
}

\begin{abstract}
Background: Epidemiological studies regarding the association between dietary fiber intake and ovarian cancer risk are still inconsistent. We aimed to review the available evidence and conduct a dose-response meta-analysis to investigate the relationship between dietary fiber intake and ovarian cancer risk.

Methods: Relevant studies were identified by searching PubMed, EMBASE, and the Cochrane Library databases before August 2017. Studies that reported relative risk (RR) estimates with 95\% confidence intervals (Cls) for the association between dietary fiber intake and risk of ovarian cancer were included. Random-effects models were used to combine the estimated effects extracted from individual study.
\end{abstract}

Results: Thirteen studies, with a total of 5777 ovarian cancer cases and 142,189 participants, met the inclusion criteria. The pooled multivariable RRs of ovarian cancer for the highest vs. the lowest category of dietary fiber intake was 0.78 (95\% Cl: $0.70,0.88)$ with no evidence of heterogeneity $\left(I^{2}=4.20 \%, P=0.40\right)$. Our dose-response analysis also showed a significant inverse association between dietary fiber intake and ovarian cancer risk (an increment of $10 \mathrm{~g} /$ day; combined RR: $0.88 ; 95 \% \mathrm{Cl}: 0.82,0.93$ ). There was no evidence for a nonlinear association ( $P$ for nonlinearity $=0.83$ ).

Conclusions: This meta-analysis suggests a significant inverse dose-response association between dietary fiber intake and ovarian cancer risk. Further studies with prospective design that take account of more potential confounders are warranted to confirm this association.

Keywords: Ovarian cancer, Protective factor, Dietary fiber, Meta-analysis

\section{Introduction}

Ovarian cancer, the second most common female reproductive malignant tumor (240,000 new cases annually) and the leading cause of death in gynecological malignancy (over 150,000 new deaths annually) worldwide [1], has caused heavy public health burden. In spite of recent advances in surgical treatment, prognosis of ovarian cancer remains poor [2]. Thus, it is of prior importance to identify the significant risks and the protective factors associated with the incidence of ovarian cancer.

Epidemiologic studies have suggested that dietary factors play an important role in the etiology of ovarian

\footnotetext{
* Correspondence: than927@163.com; yonghongqin@sohu.com; he_dong1102@126.com

†Bowen Zheng, Hui Shen and Hedong Han contributed equally to this work. 2Department of Pharmacognosy, School of Pharmacy, Second Military Medical University, 325 Guohe Road, Shanghai 200433, China

${ }^{1}$ Department of Plastic Surgery, Second Hospital of Lanzhou University, Lanzhou 730030, Gansu Province, China

Full list of author information is available at the end of the article
}

cancer, including dietary glycemic load [3], fat [4], dietary phytoestrogen [5], fruit and vegetable [6]. Fiber, mainly consumed through diet with cereal, fruit, and vegetable, was reported to be inversely associated with many types of cancers, such as colorectal cancer [7], breast cancer [8], gastric cancer [9] and endometrial cancer [10]. However, reports regarding the association between dietary fiber intake and risk of ovarian cancer were still conflicting. Six case-control studies suggested that dietary fiber intake was inversely related to risk of ovarian cancer [11-16], while others failed to find similar significant association [5, 17-22]. In addition, the effects of dietary fiber intake on ovarian cancer risk seemed to vary with different types and sources of fiber.

Thus, we conducted this meta-analysis with the following purposes: 1) to comprehensively summarize all the available evidence from case-control and cohort studies on the relationship between dietary fiber and risk 
of ovarian cancer; 2) to examine the discrepancy of ovarian cancer risk according to study design, geographic location and types or sources of fiber; 3 ) to explore the potential dose-response relationship between dietary fiber intake and risk of ovarian cancer.

\section{Materials and methods}

\section{Search strategy}

The review was registered in PROSPERO-international prospective register of systematic reviews http:// www.crd.york.ac.uk/prospero/ (registration number. CRD42016046795).We followed the standard MOOSE [23] and PRISMA criteria [24] to conduct and report this meta-analysis using the databases of PubMed, EMBASE, and the Cochrane library till August 2017. Two investigators (BWZ and HDH) independently identified publications through title and abstract. The eligibility of the publications was further evaluated by full-text assessment. Disagreements between the reviewers were resolved by discussion. We used the following search terms: (diet OR dietary OR fiber OR fibre) AND (ovary OR ovarian) AND (cancer OR neoplasm OR carcinoma OR tumor OR malignancy). Furthermore, the reference lists of retrieved articles were manually scrutinized to identify potential relevant studies.

\section{Study selection}

Eligible studies were included in the meta-analysis if they met the following criteria: 1) the study design was observational (case-control, nested case-control or cohort study); 2) the exposure of interest was dietary fiber intake, and the outcome of interest was ovarian cancer risk; 3) the risk estimates, such as relative risks, odds ratios, or hazard ratios with $95 \%$ confidence intervals (CIs) were reported; 4) factors were adjusted for ovarian cancer risk.

\section{Data extraction}

Two reviewers (BWZ, HHD) independently extracted the data from eligible studies using a predefined data extraction form. The following study characteristics were recorded from each study: the first author's last name, year of publication, study location, study design, No. of participants, No. of cases, dietary assessment, exposure details, contrast (highest vs. lowest), RR (95\% CI) (highest vs. lowest), adjustments and New-castle-Ottawa Scale (NOS) score. Validated FFQs meant that FFQs used in the included studies was previously validated. Quality assessment for studies was conducted using the 9-star NOS score [25]. Studies with an NOS score of $\geq 7$ were considered high-quality.

\section{Statistical analysis}

Relative risk was used as the common measure of association across the included studies [26]. The DerSimonian and Laird random-effects model [27, 28], which considered both within-study and between-study variation, was used to pool the estimated effects for the highest vs. the lowest categories of dietary fiber intake.

For the dose-response meta-analysis, we used generalized least-squares regression, which considered the correlation between estimates for different exposure levels, to compute study-specific risk estimates [29, 30]. Meanwhile, to examine a potential nonlinear association, we performed a two-stage random-effect dose-response meta-analysis using restricted cubic splines with three knots at fixed percentiles (10,50, and 90\%) of the distribution [31]. A $P$-value for non-linearity was calculated by testing null hypothesis that the coefficient of the second spline was equal to zero. The midpoint or median dietary fiber intake in each category was used as the assigned dose, and half the width of the adjacent category was used to define the corresponding point for the open categories.

Forest plots were used to assess the RR estimates and corresponding 95\% CIs. $\mathrm{I}^{2}$ statistics were used to assess statistical heterogeneity among the studies [32]. The subgroup and meta-regression analyses were conducted according to geographic location, type of control subjects, sample size, study design and adjustments for potential confounders. Publication bias was assessed through the Egger's regression test [33] and funnel plot. We also conducted sensitivity analysis by omitting one study at a time to investigate the influence of a single study on the overall risk estimate.

Stata Version 12.0 software (Stata Corp, College Station, TX) was used for all analyses, and $P$-value $<0.05$ was considered to be statistically significant.

\section{Results}

\section{Study characteristics}

Our literature search identified 4665 articles and 4641 were excluded after review of title or abstract (Fig. 1). Twenty-four full-text articles were further reviewed. We excluded 11 studies due to the following reasons: 7 studies did not reported RRs or 95\% CI; 2 were review [34, 35]; 2 reported duplicate population [36, 37]. Thus, 13 studies that contained 5,777 ovarian cancer cases and 142,189 participants, published between 1994 and 2015, were included in this meta-analysis. The characteristics of the included studies were summarized in Table 1. Of the 13 studies, 10 were case-control [11-17, 19-21] and 3 were cohort studies [5, 18, 22]. Among these studies, 6 were conducted in USA $[12,15,17,18,21,22], 2$ in Australia [11, 13], 2 in Canada [16, 19], 1 in Italy [14], 1 in Sweden [5] and 1 in Mexico [20]. All the included studies provided RRs that were adjusted for energy intake and most provided RRs that were adjusted for age, oral contraceptive use, menopausal status and parity. All 


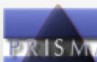

PRISMA 2009 Flow Diagram

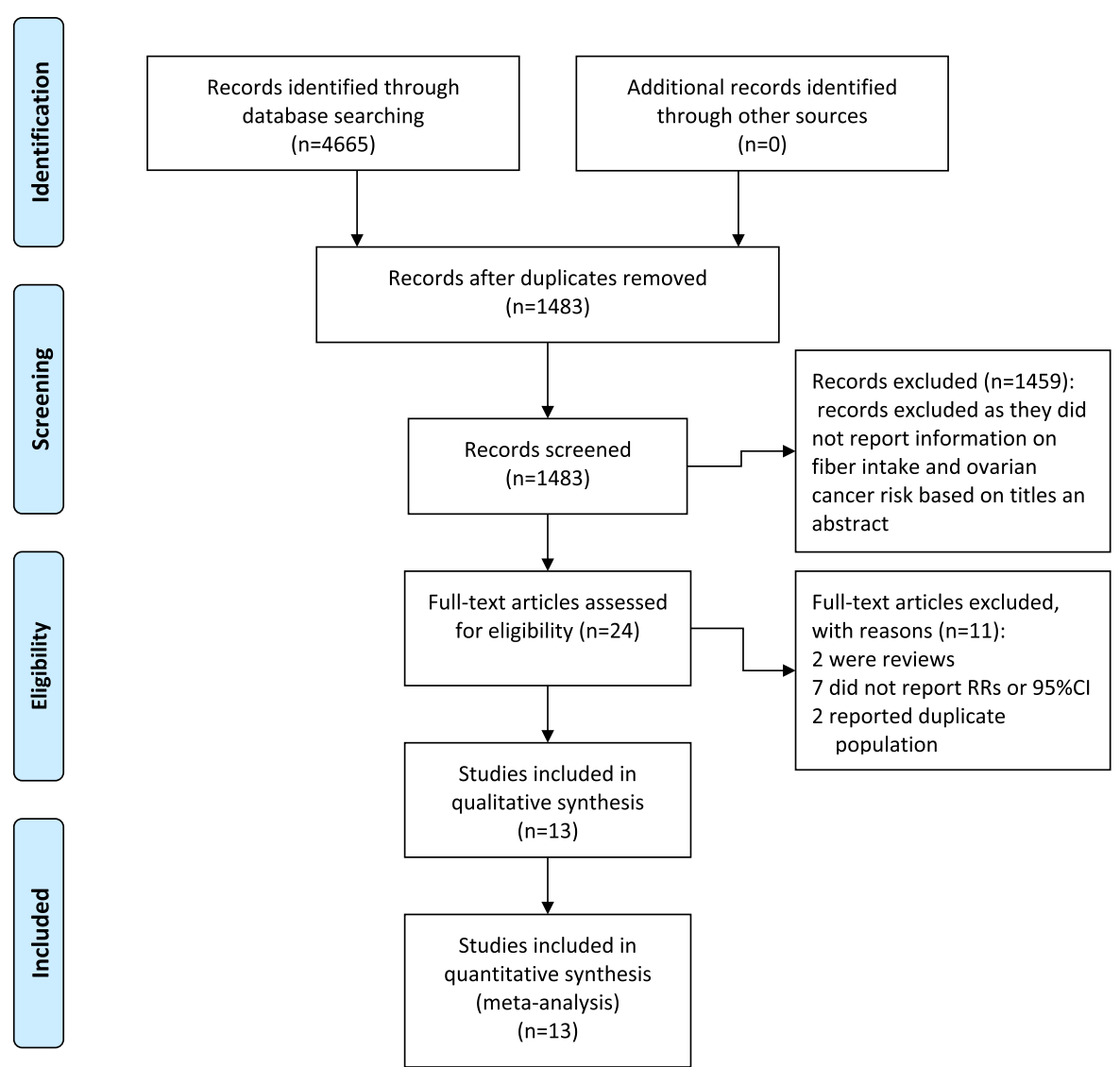

Fig. 1 Selection of studies for inclusion in this meta-analysis

the original studies measured dietary intakes using a food-frequency questionnaire. NOS scores ranged from 6 to 8 , and 7 studies were considered high quality.

\section{Dietary fiber intake and ovarian cancer risk}

The multivariable-adjusted RR for each study and the combined RR for the highest vs. the lowest categories of dietary fiber intake were shown in Fig. 2. The pooled RR was 0.78 (95\% CI: 0.70, 0.88) with no evidence of heterogeneity across the included studies $\left(\mathrm{I}^{2}=4.20 \%, P=0.40\right)$.

\section{Dose-response analysis}

Nine studies were included in the dose-response analysis (Fig. 3). The summarized RR for ovarian cancer per $10 \mathrm{~g} /$ day increase of dietary fiber intake was $0.88(95 \%$ CI: $0.82,0.93)$ without heterogeneity $\left(\mathrm{I}^{2}=7.3 \%, P=\right.$ 0.38). There was no evidence for a nonlinear association between dietary fiber intake and ovarian cancer risk $(P$ for nonlinearity $=0.83$ ).

\section{Subgroup and meta-regression analyses}

The results of subgroup analysis regarding the relationship between dietary fiber intake and risk of ovarian cancer were shown in Table 2 . When stratified by study design, the pooled RR was 0.77 (95\% CI: 0.66, 0.90) for case-control studies and 0.84 (95\% CI: $0.65,1.10)$ for cohort studies. In the subgroup analyses by number of cases, the RR was 0.83 $(95 \%$ CI: $0.65,1.07)$ for a sample size $<300$ and $0.77(95 \%$ CI: $0.67,0.87$ ) for a sample size $\geq 300$. In the subgroup analyses by fiber source and fiber type, the RR was 0.80 ( $95 \%$ CI: $0.50,1.16)$ for vegetable fiber, $0.90(0.73,1.11)$ for fruit fiber, 1.24 (95\% CI: $1.02,1.51)$ for cereal fiber, 0.79 (95\% CI: 0.51, 1.23) for soluble fiber and 0.60 (95\% CI: $0.42,0.86)$ for insoluble fiber. The inverse association became insignificant without adjusting for oral contraceptive use (RR: 0.97 ; 95\% CI: $0.76,1.24$ ) or menopausal status (RR: 0.86; 95\% CI: 0.66, 1.11). Meta-regression analysis showed that no variables might account for the heterogeneity across studies (Table 2). 


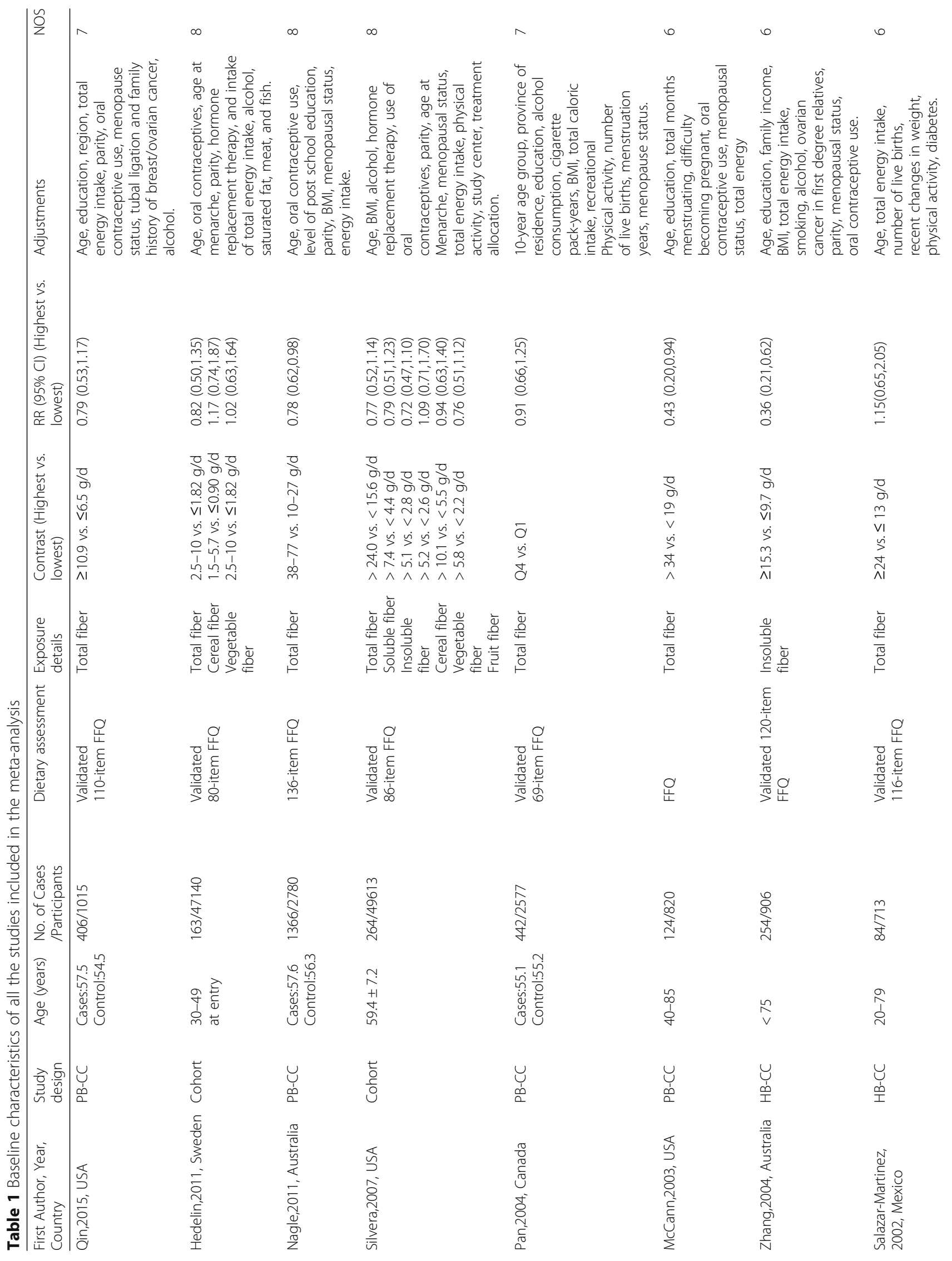




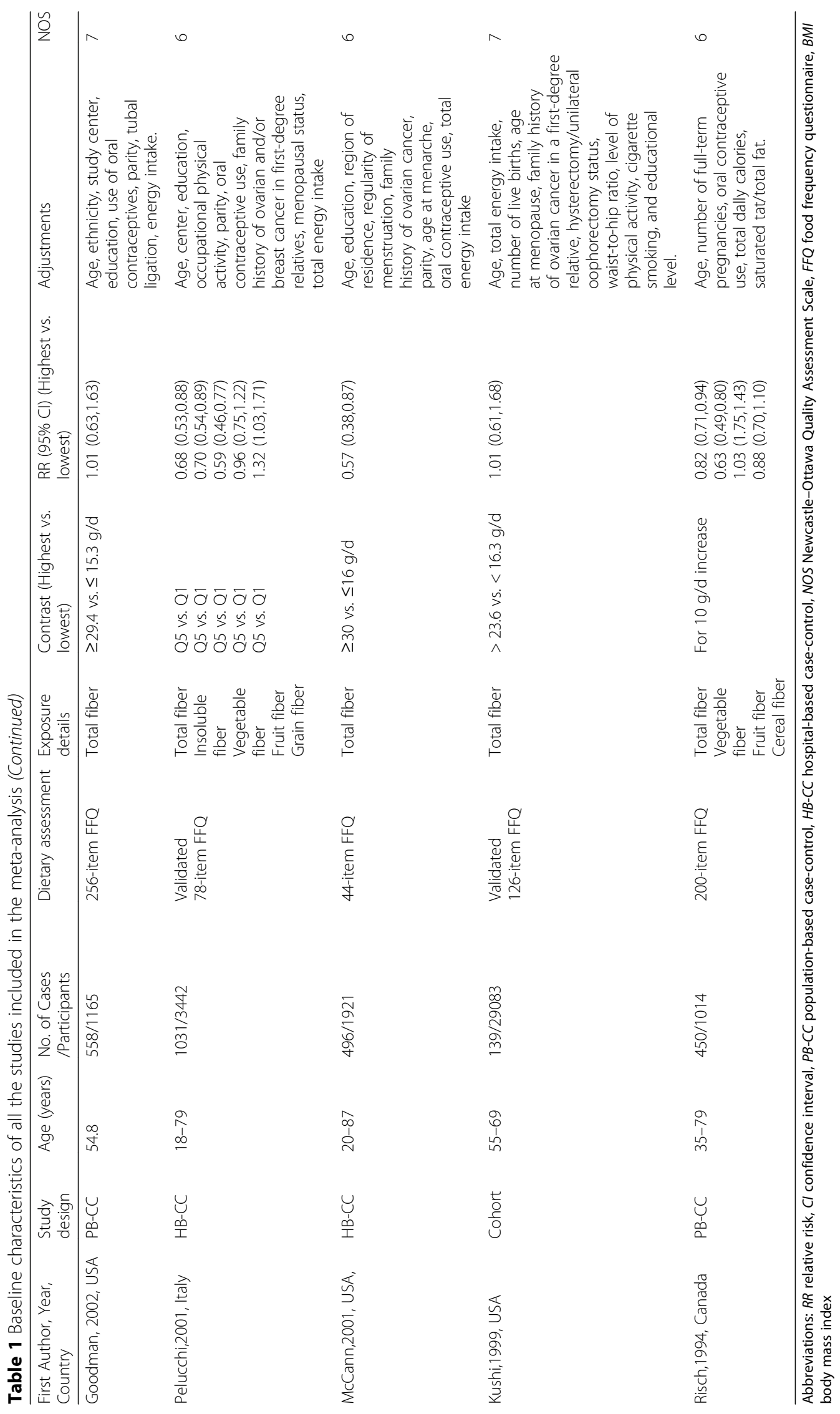




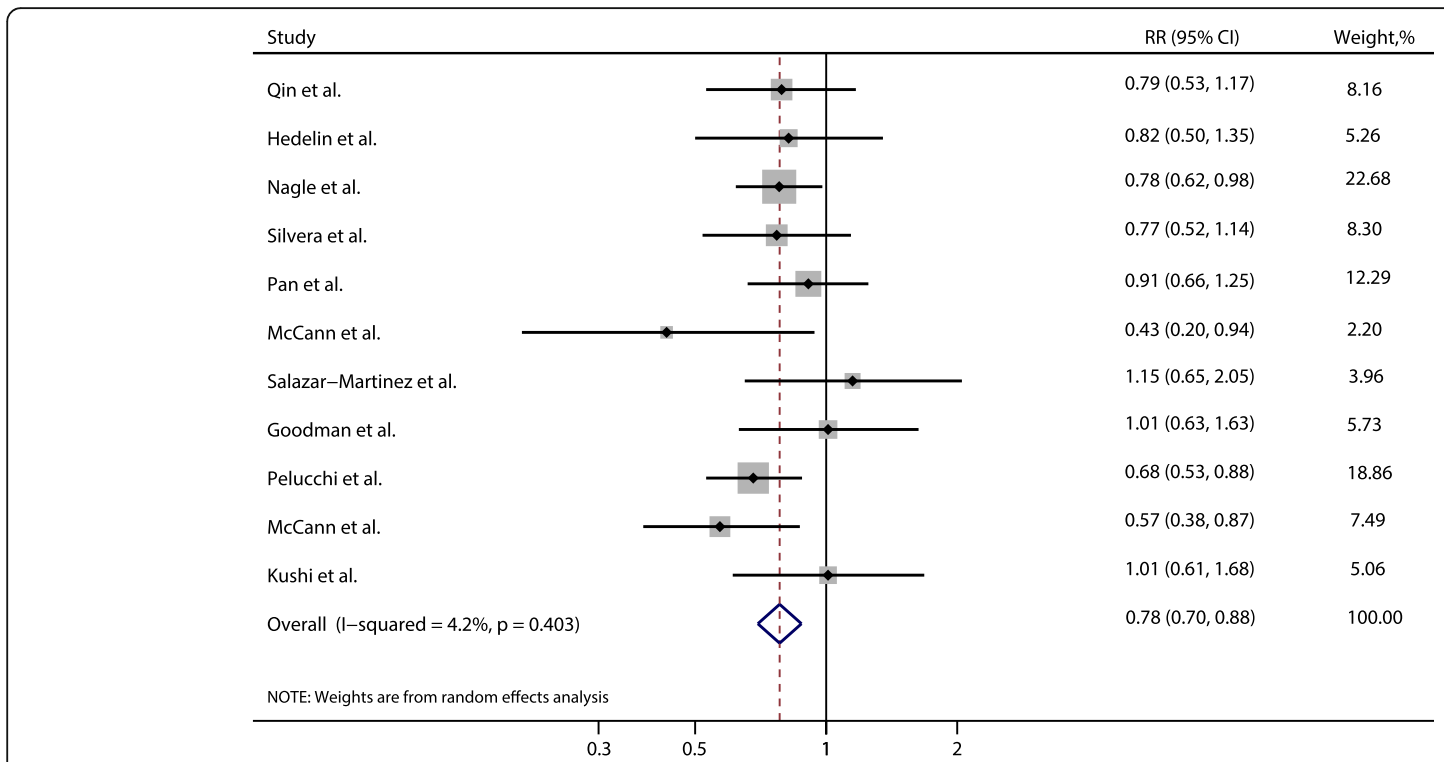

Fig. 2 Forest plot of dietary fiber intake and risk of ovarian cancer for highest vs. lowest categories

\section{Publication bias and sensitivity analysis}

Funnel plot shapes demonstrated a symmetrical distribution (Fig. 4) and no evidence of publication bias was detected by the Egger's regression test $(p=0.73)$. Sensitivity analysis shown that none of the studies influenced the combined results substantially, with a range from 0.77 (95\% CI: $0.68,0.87$ ) to 0.81 (95\% CI: 0.71, 0.91).

\section{Discussion}

To the best of our knowledge, this is the first meta-analysis to summarize evidence between total dietary fiber intake and different types or sources of dietary fiber intake and risk of ovarian cancer. The meta-analysis of 13 observational studies involving 5,777 ovarian cancer cases supports the hypothesis that a significant inverse association between dietary fiber intake and risk of ovarian cancer. The risk of ovarian cancer was reduced by $22 \%$ in the group of highest dietary fiber intake compared with the lowest. Furthermore, a 12\% reduction in risk of ovarian cancer was found for per $10 \mathrm{~g}$ increase per day. No evidence for a nonlinear association between dietary fiber intake and ovarian cancer was found.

Although no evidence of heterogeneity was found across the included studies, we conducted subgroup analyses to test whether the effect of dietary fiber intake on ovarian cancer risk differed in subpopulations. In the

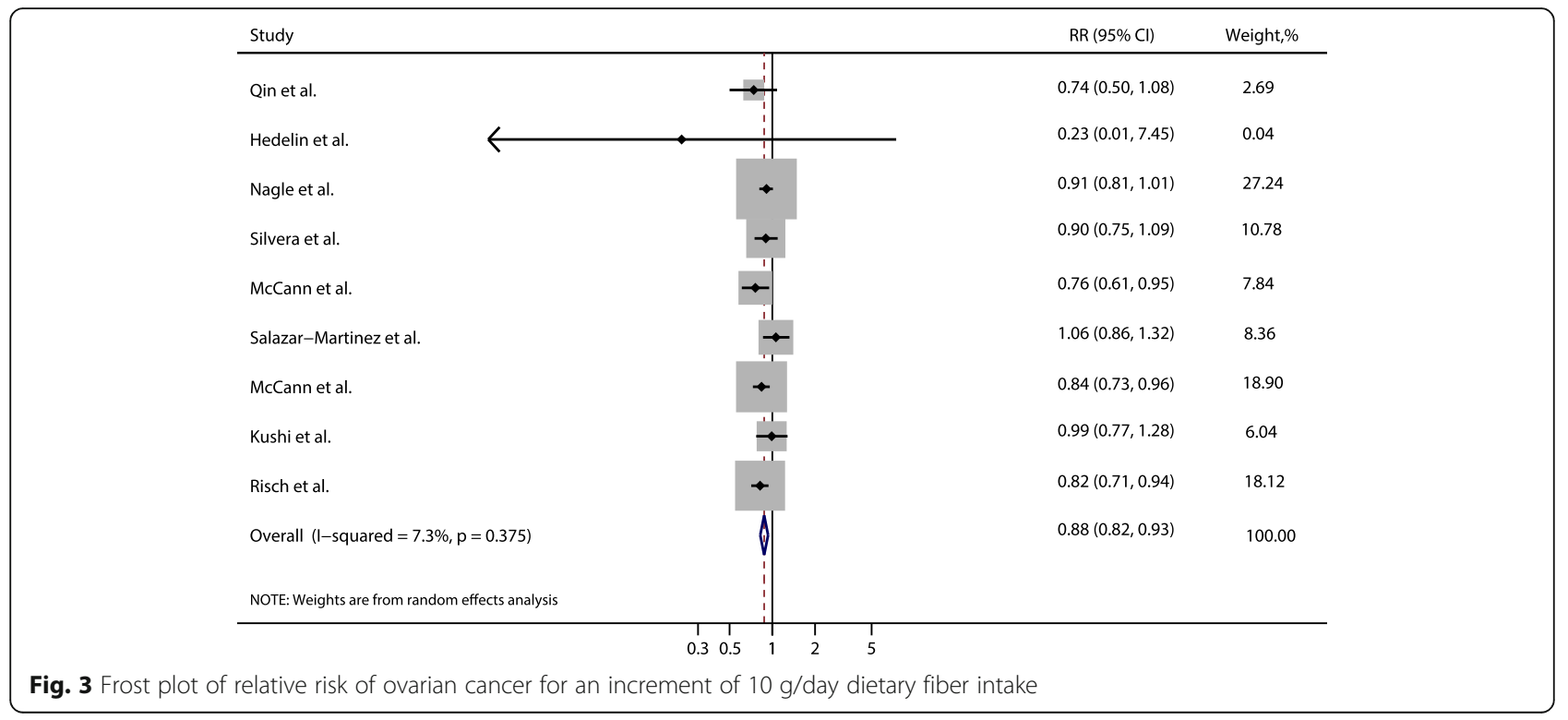


Table 2 Subgroup analysis of dietary fiber intake and ovarian cancer risk

\begin{tabular}{|c|c|c|c|c|c|}
\hline Subgroup & Studies, n & $\mathrm{RR}(95 \% \mathrm{Cl})$ & $I^{2}(\%)$ & $P^{a}$ & $p^{b}$ \\
\hline Total & 11 & $0.78(0.70,0.88)$ & 4.20 & 0.40 & \\
\hline \multicolumn{6}{|l|}{ Study design } \\
\hline Case-control & 8 & $0.77(0.66,0.90)$ & 25 & 0.23 & \multirow[t]{2}{*}{0.17} \\
\hline Cohort & 3 & $0.84(0.65,1.10)$ & 0 & 0.70 & \\
\hline \multicolumn{6}{|c|}{ Type of control subjects } \\
\hline Population-based & 8 & $0.82(0.72,0.94)$ & 0 & 0.69 & \multirow[t]{2}{*}{0.16} \\
\hline Hospital-based & 3 & $0.72(0.52,0.99)$ & 48.20 & 0.15 & \\
\hline \multicolumn{6}{|l|}{ Geographic location } \\
\hline North America & 7 & $0.79(0.66,0.95)$ & 19.40 & 0.28 & \multirow[t]{2}{*}{0.87} \\
\hline Others & 4 & $0.77(0.66,0.89)$ & 0 & 0.41 & \\
\hline \multicolumn{6}{|l|}{ No. of cases } \\
\hline$<300$ & 5 & $0.83(0.65,1.07)$ & 15.40 & 0.32 & \multirow[t]{2}{*}{0.16} \\
\hline$\geq 300$ & 6 & $0.77(0.67,0.87)$ & 5.10 & 0.38 & \\
\hline \multicolumn{6}{|l|}{ Study quality } \\
\hline NOS $<7$ & 4 & $0.68(0.50,0.91)$ & 42.90 & 0.15 & \multirow[t]{2}{*}{0.09} \\
\hline $\mathrm{NOS} \geq 7$ & 7 & $0.84(0.73,0.96)$ & 0 & 0.92 & \\
\hline \multicolumn{6}{|l|}{ Validation FFQ } \\
\hline Yes & 7 & $0.81(0.70,0.93)$ & 0 & 0.60 & \multirow[t]{2}{*}{0.59} \\
\hline No & 4 & $0.72(0.54,0.94)$ & 43.00 & 0.15 & \\
\hline \multicolumn{6}{|l|}{ Fiber type } \\
\hline Vegetable fiber & 3 & $0.80(0.55,1.16)$ & 66.90 & 0.05 & \\
\hline Fruit fiber & 2 & $0.90(0.73,1.11)$ & 0 & 0.32 & \\
\hline Cereal fiber & 3 & $1.24(1.02,1.51)$ & 0 & 0.73 & \\
\hline \multicolumn{6}{|l|}{ Fiber source } \\
\hline Soluble fiber & 1 & $0.79(0.51,1.23)$ & - & - & \\
\hline Insoluble fiber & 3 & $0.60(0.42,0.86)$ & 61.00 & 0.08 & \\
\hline \multicolumn{6}{|l|}{ Adjustments } \\
\hline \multicolumn{6}{|l|}{$\mathrm{BMI}$} \\
\hline Yes & 3 & $0.81(0.69,0.96)$ & 0 & 0.71 & \\
\hline No & 8 & $0.77(0.64,0.92)$ & 25.40 & 0.23 & \\
\hline \multicolumn{6}{|l|}{ Parity } \\
\hline Yes & 10 & $0.79(0.70,0.89)$ & 0 & 0.52 & \\
\hline No & 1 & $0.43(0.20,0.93)$ & - & - & \\
\hline \multicolumn{6}{|l|}{ Oral contraceptive use } \\
\hline Yes & 8 & $0.74(0.65,0.84)$ & 0 & 0.54 & \\
\hline No & 3 & $0.97(0.76,1.24)$ & 0 & 0.77 & \\
\hline \multicolumn{6}{|l|}{ physical activity } \\
\hline Yes & 6 & $0.80(0.70,0.91)$ & 0 & 0.46 & \\
\hline No & 5 & $0.73(0.57,0.94)$ & 24.80 & 0.26 & \\
\hline \multicolumn{6}{|l|}{ Menopausal status } \\
\hline Yes & 6 & $0.76(0.67,0.86)$ & 0 & 0.53 & \\
\hline No & 5 & $0.86(0.66,1.11)$ & 28.70 & 0.23 & \\
\hline
\end{tabular}

Abbreviations: $R R$ relative risk, $C l$ confidence interval, NOS NewcastleOttawa Quality Assessment Scale, $B M I$ body mass index, $P$-value ${ }^{a}, p$ for heterogeneity within each subgroup, $P$-value ${ }^{\mathrm{b}}, \mathrm{p}$ for heterogeneity between subgroups analysis stratified by study design, protective effect of dietary fiber intake was significant in case-control studies but not in cohort studies. There were only three cohort studies with 566 cancer cases, which might not have sufficient power to detect a statistically significant effect. In addition, null association in studies with a relatively small sample size (No. of cases $<300$ ) may also be explained by insufficient statistical power. Additionally, we observed a significant positive association with cereal fiber intake, which probably caused by a high ratio between starch and fiber intake in the Italian population in the study conducted by Pelucchi et al. [14], as the potential promotional action of starch may overwhelm possible protective action of fiber. However, this result should be interpreted carefully and confirmed by further studies because of limited information. The present meta-analysis also indicated that the association was significantly modified by oral contraceptive use and menopausal status, which was corresponding to the previous studies that ovarian cancer risk differed by menopausal status [38] and oral contraceptive use [39].

Several plausible mechanisms have been proposed to explain the hypothesis that dietary fiber intake protects against ovarian cancer. Dietary fiber may decrease circulating estrogen concentrations by changing bacterial macroflora, increasing excretion and consequently lowering serum levels and availability of oestrogens, which reduces the bioavailability of steroid hormones, which in turn is related to the progression of ovarian cancer [8, 40-42]. In addition to the estrogen-related pathway, dietary fiber is believed to reduce glycemic load and improve insulin sensitivity, thus influence insulin-like growth factors which are suggested to be risk factor for ovarian cancer $[43,44]$.

Our study had several important strengths. This meta-analysis involving 5,777 ovarian cancer cases comprehensively assessed the association between dietary fiber intake and ovarian cancer risk without heterogeneity across studies, enhancing the statistical power to detect a significant association and providing more precise risk estimates. Moreover, most of the included studies were adjusted for important confounders, such as age, energy intake, parity and oral contraceptive use. The sensitivity analysis showed stable and robust results after removal of one study at a time. In addition, outcomes assessment with regards to diagnosis of ovarian cancer in the included studies were histologically confirmed. Finally, the significant inverse dose-response relationship found in this meta-analysis strengthened the association between dietary fiber intake and risk of ovarian cancer.

Potential limitations should be considered in this study. First, we had no access to the individual patient-level data, which would provide a more reliable assessment of relationship between dietary fiber intake 


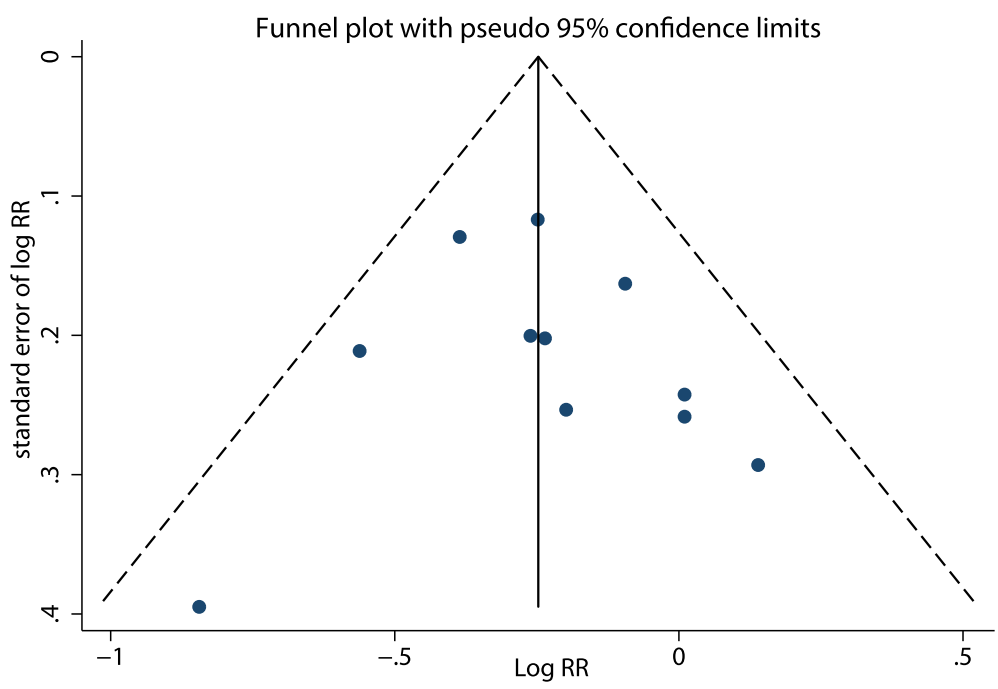

Fig. 4 Funnel plot of studies reporting dietary fiber intake and ovarian cancer risk

and risk of ovarian cancer. Second, the results in our study were mainly based on case-control studies, which may introduce selection bias or recall bias that were inherited in retrospective studies. Third, in observational studies, other factors potentially accounted for the observed association cannot be ruled out. However, potential confounders including energy intake, parity and oral contraceptive use were adjusted in the included studies and the inverse association persisted when analyses were restricted to studies that adjusted for these confounders. Fourth, assessing dietary fiber intake with an FFQ at baseline could have led to overestimation of the range of fiber intake and thus may underestimate the pooled relative risk $[45,46]$. Information on the "validated FFQs" was extracted from studies included in this meta-analysis, which meant that the tools used for quantitative dietary measurements were reported with some sort of evaluation in these studies. The evaluation may be tested only in a specific population/setting of interest and for the dietary components of interest but was probably related to smaller bias comparing with the untested FFQs. Moreover, result of subgroup analysis suggested that the inverse association remained significant without application of a validated FFQ. Fifth, the estimates of fiber intakes from different dietary assessment methods and different compositional databases could account for discrepancy among the included studies, so results from this meta-analysis should be interpreted cautiously. Sixth, data in this meta-analysis was mainly from western population, further studies concerning other populations were warranted to generalize this inverse association.

Fiber is mainly consumed through daily diet with cereal, fruit, and vegetable. The mean dietary fiber intake in United States and most European countries is $15 \mathrm{~g} /$ day, which is considerably less than the recommended amount (approximately 25-38 g/day) [47, 48]. Considering the public health burden of ovarian cancer, increasing dietary fiber intake in the general population is of importance for ovarian cancer prevention.

\section{Conclusion}

This meta-analysis provides evidence for the hypothesis that a higher intake of dietary fiber is inversely associated with ovarian cancer risk, consistent with a dose-response relationship. This evidence is largely limited to case-control studies. Further studies with prospective design that are adequately adjusted for potential confounders and clarified types or sources of fiber are needed to confirm our findings.

\section{Abbreviations}

BMI: body mass index; Cl: confidence interval; FFQ: food frequency questionnaire; HB-CC: hospital-based case-control; NOS: Newcastle-Ottawa Quality Assessment Scale; PB-CC: population-based case-control; RR: relative risk

\section{Acknowledgements}

The authors thank the staff of the Department of Health Statistics, Second Military Medical University, China and Department of Pharmacognosy, School of Pharmacy, Second Military Medical University, China for their dedicated assistance in literature searching and screening.

\section{Funding}

None.

\section{Availability of data and materials}

All data generated or analyzed during the current study are included in this published article and its additional files.

\section{Authors' contributions}

BWZ, HS and HDH made study protocol, designed the research and performed the literature search. BWZ and HDH had full access to the study data and carried out all analysis. BWZ and HDH wrote the draft of this paper. $\mathrm{HS}$ and $\mathrm{TH}$ revised the article critically; and all authors contributed to the 
manuscript writing, made critical revision, read and approved the final manuscript.

\section{Ethics approval and consent to participate Not applicable.}

\section{Consent for publication}

Not applicable.

\section{Competing interests}

All of the authors declare that they have no competing interest.

\section{Publisher's Note}

Springer Nature remains neutral with regard to jurisdictional claims in published maps and institutional affiliations.

\section{Author details}

'Department of Plastic Surgery, Second Hospital of Lanzhou University, Lanzhou 730030, Gansu Province, China. ²Department of Pharmacognosy, School of Pharmacy, Second Military Medical University, 325 Guohe Road, Shanghai 200433, China. ${ }^{3}$ Department of Health Statistics, Second Military Medical University, Shanghai 200433, China.

\section{Received: 6 February 2018 Accepted: 17 October 2018}

\section{Published online: 30 October 2018}

\section{References}

1. Torre LA, Bray F, Siegel RL, Ferlay J, Lortet-Tieulent J, Jemal A. Global cancer statistics, 2012. CA Cancer J Clin. 2015;65:87-108.

2. Falconer $H$, Yin $L$, Gronberg $H$, Altman D. Ovarian cancer risk after salpingectomy: a nationwide population-based study. J Natl Cancer Inst. 2015;107:dju410.

3. Turati F, Galeone C, Gandini S, Augustin LS, Jenkins DJ, Pelucchi C, La Vecchia C. High glycemic index and glycemic load are associated with moderately increased cancer risk. Mol Nutr Food Res. 2015;59:1384-94.

4. Qiu W, Lu H, Qi Y, Wang X. Dietary fat intake and ovarian cancer risk: meta-analysis of epidemiological studies. Oncotarget. 2016;7:37390-406.

5. Hedelin M, Lof M, Andersson TML, Adlercreutz H, Weiderpass E. Dietary phytoestrogens and the risk of ovarian Cancer in the Women's lifestyle and health cohort study. Cancer Epidemiol Biomark Prev. 2011;20:308-17.

6. Tang L, Lee AH, Su D, Binns CW. Fruit and vegetable consumption associated with reduced risk of epithelial ovarian cancer in southern Chinese women. Gynecol Oncol. 2014;132:241-7.

7. Kunzmann AT, Coleman HG, Huang WY, Kitahara CM, Cantwell MM, Berndt SI. Dietary fiber intake and risk of colorectal cancer and incident and recurrent adenoma in the prostate, lung, colorectal, and ovarian Cancer screening trial. Am J Clin Nutr. 2015:102:881-90.

8. Aune D, Chan DS, Greenwood DC, Vieira AR, Rosenblatt DA, Vieira R, Norat T. Dietary fiber and breast cancer risk: a systematic review and meta-analysis of prospective studies. Ann Oncol. 2012;23:1394-402.

9. Zhang Z, Xu G, Ma M, Yang J, Liu X. Dietary Fiber intake reduces risk for gastric Cancer: a meta-analysis. Gastroenterology. 2013;145:113-20.

10. Bidoli E, Pelucchi C, Zucchetto A, Negri E, Dal Maso L, Polesel J, Montella M, Franceschi S, Serraino D, La Vecchia C, Talamini R. Fiber intake and endometrial cancer risk. Acta Oncol. 2010;49:441-6.

11. Nagle CM, Kolahdooz F, Ibiebele TI, Olsen CM, Lahmann PH, Green AC, Webb PM. Carbohydrate intake, glycemic load, glycemic index, and risk of ovarian cancer. Ann Oncol. 2011;22:1332-8.

12. McCann SE, Freudenheim JL, Marshall JR, Graham S. Risk of human ovarian cancer is related to dietary intake of selected nutrients, phytochemicals and food groups. J Nutr. 2003;133:1937-42.

13. Zhang M. Reproductive and dietary risk factors for epithelial ovarian cancer in China. Gynecol Oncol. 2004;92:320-6.

14. Pelucchi C, La Vecchia C, Chatenoud L, Negri E, Conti E, Montella M, Calza S, Dal Maso L, Franceschi S. Dietary fibres and ovarian cancer risk. Eur J Cancer. 2001;37:2235-9.

15. McCann SE, Moysich KB, Mettlin C. Intakes of selected nutrients and food groups and risk of ovarian cancer. Nutr Cancer. 2001;39:19-28.

16. Risch HA, Jain M, Marrett LD, Howe GR. Dietary fat intake and risk of epithelial ovarian cancer. J Natl Cancer Inst. 1994;86:1409-15.
17. Qin B, Moorman PG, Alberg AJ, Barnholtz-Sloan JS, Bondy M, Cote ML, Funkhouser E, Peters ES, Schwartz AG, Terry P, Schildkraut JM, Bandera EV. Dietary carbohydrate intake, glycaemic load, glycaemic index and ovarian cancer risk in African-American women. Br J Nutr. 2016;115:694-702.

18. Silvera SAN, Jain M, Howe GR, Miller AB, Rohan TE. Dietary fiber intake and ovarian cancer risk: a prospective cohort study. Cancer Causes Control. 2007; 18:335-41.

19. Pan SY, Ugnat AM, Mao Y, Wen SW, Johnson KC. A case-control study of diet and the risk of ovarian cancer. Cancer Epidemiol Biomark Prev. 2004;13:1521-7.

20. Salazar-Martinez E, Lazcano-Ponce EC. Gonzalez lira-lira G, Escudero-De Los Rios P, Hernandez-Avila M: nutritional determinants of epithelial ovarian cancer risk: a case-control study in Mexico. Oncology. 2002;63:151-7.

21. Goodman MT. Association of Dairy Products, lactose, and calcium with the risk of ovarian Cancer. Am J Epidemiol. 2002;156:148-57.

22. Kushi LH, Mink PJ, Folsom AR, Anderson KE, Zheng W, Lazovich D, Sellers TA. Prospective study of diet and ovarian cancer. Am J Epidemiol. 1999;149: 21-31.

23. Stroup DF, Berlin JA, Morton SC, Olkin I, Williamson GD, Rennie D, Moher D, Becker BJ, Sipe TA, Thacker SB. Meta-analysis of observational studies in epidemiology: a proposal for reporting. Meta-analysis of observational studies in epidemiology (MOOSE) group. Jama. 2000;283:2008-12

24. Liberati A, Altman DG, Tetzlaff J, Mulrow C, Gotzsche PC, loannidis JP, Clarke M, Devereaux PJ, Kleijnen J, Moher D. The PRISMA statement for reporting systematic reviews and meta-analyses of studies that evaluate health care interventions: explanation and elaboration. PLoS Med. 2009:6:e1-e34.

25. Wells GA, Shea B, O'Connell D, Peterson J, Welch V, et al. (2011) The Newcastle-Ottawa Scale (NOS) for assessing the quality of nonrandomized studies in meta-analysis. Available: www.ohri.ca/programs/clinical_ epidemiology/oxford.asp. Accessed 25 November 2012.

26. Zhang J, Yu KF. What's the relative risk? A method of correcting the odds ratio in cohort studies of common outcomes. Jama. 1998;280:1690-1.

27. Jackson D, White $\mathbb{R}$, Thompson SG. Extending DerSimonian and Laird's methodology to perform multivariate random effects meta-analyses. Stat Med. 2010:29:1282-97.

28. Borenstein M, Higgins JP. Meta-analysis and subgroups. Prev Sci. 2013;14: 134-43.

29. Orsini NBCRG. Generalized least squares for trend estimation of summarized dose-response. Stata J. 2006:6:40-57.

30. Greenland S, Longnecker MP. Methods for trend estimation from summarized dose-response data, with applications to meta-analysis. Am J Epidemiol. 1992;135:1301-9.

31. Larsson SC, Orsini N, Wolk A. Vitamin B6 and risk of colorectal cancer: a meta-analysis of prospective studies. JAMA. 2010;303:1077-83.

32. Higgins JP, Thompson SG, Deeks JJ, Altman DG. Measuring inconsistency in meta-analyses. Bmj. 2003;327:557-60.

33. Egger M, Davey Smith G, Schneider M, Minder C. Bias in meta-analysis detected by a simple, graphical test. Bmj. 1997;315:629-34.

34. Crane TE, Khulpateea BR, Alberts DS, Basen-Engquist K, Thomson CA. Dietary intake and ovarian cancer risk: a systematic review. Cancer Epidemiology Biomarkers and Prevention. 2014;23:255-73.

35. Brekelmans $C T$. Risk factors and risk reduction of breast and ovarian cancer. Curr Opin Obstet Gynecol. 2003;15:63-8.

36. Qin B, Moorman PG, Kelemen LE, Alberg AJ, Barnholtz-Sloan JS, Bondy M, Cote ML, Funkhouser E, Peters ES, Schwartz AG, Terry P, Schildkraut JM, Bandera EV. Dietary quality and ovarian Cancer risk in African-American women. Am J Epidemiol. 2017;185:1281-9.

37. Qin B, Moorman PG, Alberg AJ, Barnholtz-Sloan JS, Bondy M, Cote ML, Funkhouser E, Peters ES, Schwartz AG, Terry P, Schildkraut JM, Bandera EV Dairy, calcium, vitamin D and ovarian cancer risk in African-American women. Br J Cancer. 2016;115:1122-30.

38. Moorman PG, Calingaert B, Palmieri RT, Iversen ES, Bentley RC, Halabi S, Berchuck A, Schildkraut JM. Hormonal risk factors for ovarian cancer in premenopausal and postmenopausal women. Am J Epidemiol. 2008;167: 1059-69.

39. Beral V, Doll R, Hermon C, Peto R, Reeves G. Ovarian cancer and oral contraceptives: collaborative reanalysis of data from 45 epidemiological studies including 23,257 women with ovarian cancer and 87,303 controls. Lancet. 2008;371:303-14.

40. Pillow PC, Duphorne CM, Chang S, Contois JH, Strom SS, Spitz MR, Hursting SD. Development of a database for assessing dietary phytoestrogen intake. Nutr Cancer. 1999;33:3-19. 
41. Rose DP, Goldman M, Connolly JM, Strong LE. High-fiber diet reduces serum estrogen concentrations in premenopausal women. Am J Clin Nutr. 1991;54:520-5

42. Cunat S, Hoffmann P, Pujol P. Estrogens and epithelial ovarian cancer. Gynecol Oncol. 2004;94:25-32.

43. Franceschi S, Dal Maso L, Augustin L, Negri E, Parpinel M, Boyle P, Jenkins DJ, La Vecchia C. Dietary glycemic load and colorectal cancer risk. Ann Oncol. 2001;12:173-8.

44. Yu H, Rohan T. Role of the insulin-like growth factor family in cancer development and progression. J Natl Cancer Inst. 2000;92:1472-89.

45. Prentice RL. Dietary assessment and the reliability of nutritional epidemiology reports. Lancet. 2003;362:182-3.

46. Willett WC, Sampson L, Stampfer MJ, Rosner B, Bain C, Witschi J, Hennekens $\mathrm{CH}$, Speizer FE. Reproducibility and validity of a semiquantitative food frequency questionnaire. Am J Epidemiol. 1985:122:51-65.

47. Slavin JL. Position of the American dietetic association: health implications of dietary fiber. J Am Diet Assoc. 2008;108:1716-31.

48. Lanza E, Jones DY, Block G, Kessler L. Dietary fiber intake in the US population. Am J Clin Nutr. 1987;46:790-7.

Ready to submit your research? Choose BMC and benefit from:

- fast, convenient online submission

- thorough peer review by experienced researchers in your field

- rapid publication on acceptance

- support for research data, including large and complex data types

- gold Open Access which fosters wider collaboration and increased citations

- maximum visibility for your research: over $100 \mathrm{M}$ website views per year

At BMC, research is always in progress.

Learn more biomedcentral.com/submissions 